\title{
Insulin Binding Capacity in Patients Changed from Conventional to Highly Purified Insulins An Indicator of Likely Response
}

\author{
B. E. Mustaffa, P. R. Daggett, and J.D.N. Nabarro \\ The Cobbold Laboratories, The Middlesex Hospital, London, U. K.
}

Summary. Highly purified insulins offer the possibility of reducing insulin antibody levels and insulin requirement. Those likely to respond cannot be predicted on clinical grounds and a simple laboratory test is recommended for this purpose. This is based on insulin binding capacity (IBC) of plasma and has been used to follow a group of 47 patients over six months. 47 patients previously treated with British soluble and isophane insulins were changed to highly purified Leo Neutral and Leo Retard. 36 showed a reduction of insulin requirement and two groups could be identified. An IBC of $>40 \mu \mathrm{U} / \mathrm{ml}$ was associated in $94 \%$ with a reduction of insulin dose; if the IBC was less the response was unpredictable. The initial IBC was related to the initial insulin requirement and to the eventual percentage reduction. Serial measurements in patients with high initial IBC showed a steady fall. Measurement of the IBC is a simple investigation; if the level is $>40 \mu \mathrm{U} / \mathrm{ml}$ changing to a highly purified insulin is likely to be associated with reduction of insulin requirement.

Key words: Insulin binding capacity, insulin antibodies, highly purified insulins, isophane insulin.

Highly purified insulins have recently become available and their use has been shown to be associated with a reduction of insulin requirement in some diabetics $[1,2,3]$. It is not possible to identify these patients on clinical grounds and we have sought to develop a simple test for this purpose. A modification of the measurement of the "insulin binding capacity" (IBC) described by Anderson et al. [4] has been used. Forty seven selected diabetics attending the Clinic at this hospital agreed to take part in a trial of highly purified insulins. Changes of insulin requirement have been studied in relation to those of IBC.

\section{Patients and Methods}

\section{Patients}

The patients were selected from those attending the Clinic who were taking two doses of British soluble and isophane insulins a day. They were only offered a place in the trial if they were intelligent, highlymotivated and experienced diabetics. Of those selected to take part 24 were men and 23 women; they were 13-66 years of age, required 16-80 Units/day (mean 50), had had diabetes and had been an insulin for an average of 11.5 and 10 years, respectively. After agreeing to take part they were asked to adjust their insulin over a four week period to secure the best possible control. They were then changed to the highly purified preparations (Leo Neutral and Leo Retard, Nordisk Insulin). Initially they were asked to take the same dose of insulin except for the evening dose of Leo Retard (NPH) which was reduced by $25 \%$ to minimise the risk of nocturnal hypoglycaemia. Subsequently they adjusted their insulin dose as required. The patients were seen at monthly intervals during the period of the trial; some attended a morning and others an evening clinic, but each patient attended at about the same time of day. When seen the patient was weighed, home urine test records reviewed, problems related to diabetic control discussed, insulin dose recorded and blood taken for sugar and IBC measurements. The patients have been followed for from 6-17 months. 


\section{Methods}

Assessment of Diabetic Control. This is generally accepted as being extremely difficult. Measurement of blood sugar is simple but may not be the best variable by which to judge diabetic control. Single measurements on a clinic visit may be unrepresentative and serial measurements must involve distortion of the patient's usual daily regime. We have relied on changes in body weight, the home urine test records - aiming at four tests a day - and the patient's own assessment of his or her stability.

Measurements of Insulin Binding Capacity. The method used for assessing IBC was a modification of that described by Anderson et al. [4]. This examines the distribution of labelled bovine insulin between the patient's plasma and an aliquot of guinea-pig anti-insulin serum (GP-AIS) of known binding capacity. The GP-AIS with attached ${ }^{125}$ I-insulin is precipitated and the IBC of the plasma is proportional to counts in the supernatant/counts in the precipitate; the former represents ${ }^{125} \mathrm{I}$-insulin attached to antibodies in the plasma. Anderson et al, in their original paper, noted that the IBC of patients who had never had insulin was about $30 \mu \mathrm{U} / \mathrm{ml}$ and we obtained figures of $40 \mu \mathrm{U} / \mathrm{ml}$ using fresh label and $60 \mu \mathrm{U} / \mathrm{ml}$ with label that was two weeks old. It seemed likely that these unreasonably high levels were due to free ${ }^{125}$ I-insulin or immunologicallyinactive labelled insulin that remained in the supernatant after the precipitation of the GP-AIS. A brief exposure of the supernatant to activated charcoal removed $11-30 \%$ of the label from the supernatant (depending on the age of the label) and gave IBC levels of $<5 \mu \mathrm{U} / \mathrm{ml}$ for normal subjects and diabetics who had never had insulin. This step was therefore introduced and we also used centrifugation to separate the precipitate and made estimations on undiluted plasma as described by Oakley [3].

Blood samples for IBC measurement were taken into heparinised tubes, centrifuged at $1700 \mathrm{~g}$ for $5 \mathrm{~min}$ within $15 \mathrm{~min}$ of collection and the plasma was stored at $-20^{\circ} \mathrm{C}$ while awaiting analysis.

The following special reagents were used. Guinea-pig anti-insulin serum (GP-AIS) - lot K 0575 and rabbit anti-guinea-pig serum (R-AGPS) - lot 0318 obtained from Wellcome Reagents Ltd., Beckenham, England. Bovine ${ }^{125} \mathrm{I}$-insulin (specific activity $50 \mu \mathrm{Ci} / \mathrm{ug}$ ) from the Radio-chemical Centre, Amersham, England and Norit "GSX" charcoal from Hopkin and Williams, Essex, England. All dilutions were made with $0.04 \mathrm{~mol} / 1$ sodium phosphate buffer, $\mathrm{pH} 7.4$, containing $5 \mathrm{~g} / \mathrm{l}$ bovine serum albumin.
$100 \mu \mathrm{l} \mathrm{GP}$-AIS at a dilution of 1 in 8000 (IBC $=14 \mu \mathrm{U}$ ) was incubated overnight with $100 \mu \mathrm{l}$ of R-AGPS diluted 1 in 60 . To this was added $100 \mu \mathrm{l}$ of the patient's undiluted plasma and $100 \mu \mathrm{l}$ of a solution of bovine ${ }^{125} \mathrm{I}$-insulin (containing $2 \mu \mathrm{U}$ in $100 \mu \mathrm{l})$. On the fifth day, $100 \mu \mathrm{l}$ of normal guinea-pig serum (diluted 1:50) was added to stabilise the precipitate and incubation at $4^{\circ} \mathrm{C}$ was continued for a further day. Separation was then achieved by centrifugation at $1800 \mathrm{~g}$ for $45 \mathrm{~min}$. The supernatant was removed and added to $100 \mu 1$ charcoal suspension $(5 \mathrm{~g} / 100 \mathrm{ml})$. Within $5 \mathrm{~min}$ the charcoal was precipitated by centrifugation at $1800 \mathrm{~g}$ for $30 \mathrm{~min}$ at $4^{\circ} \mathrm{C}$. The precipitate from the first centrifugation and the supernatant from the second were then counted in an automatic gamma counter for $200 \mathrm{~s}$ each.

The IBC was calculated from the equation

$\mathrm{IBC}=\frac{\left(\mathrm{Ab}^{125} \mathrm{I}\right)}{\left(\mathrm{GP}-\mathrm{AIS}{ }^{125} \mathrm{I}\right)} \times(\mathrm{GP}-\mathrm{AIS})$

where $\left(A b^{125} \mathrm{I}\right)={ }^{125} \mathrm{I}$-insulin bound to patient's insulin antibodies

(counts in final supernatant)

(GP-AIS $\left.{ }^{125} \mathrm{I}\right)={ }^{125} \mathrm{I}$-insulin bound to GP-AIS

(counts in first precipitate)

(GP-AIS) $=$ Insulin binding capacity of the $100 \mu$ of GP-AIS

The IBC is expressed in $\mu \mathrm{U} / \mathrm{ml}$. This figure for the partition of ${ }^{125}$ I-insulin reflects not only the total antibody present in the plasma but also its effective affinity constant. A reduction of IBC may result from reduction of total antibody content or in the affinity constant or both.

Statistical Methods. IBC values did not show a normal distribution and for statistical purposes log values have been used. The significance of correlation coefficients has been calculated using the ' $t$ ' test, and the comparison of blood sugars and body weights by paired ' $t$ ' test. For the calculation of significant differences between two groups the Chisquare test with Yates' correction has been used.

\section{Results}

Of the 47 patients, 36 showed a reduction in insulin requirement and in the remainder there was either no change or an actual increase (Fig. 1). It is, however, essential to show that the reduction of dose 


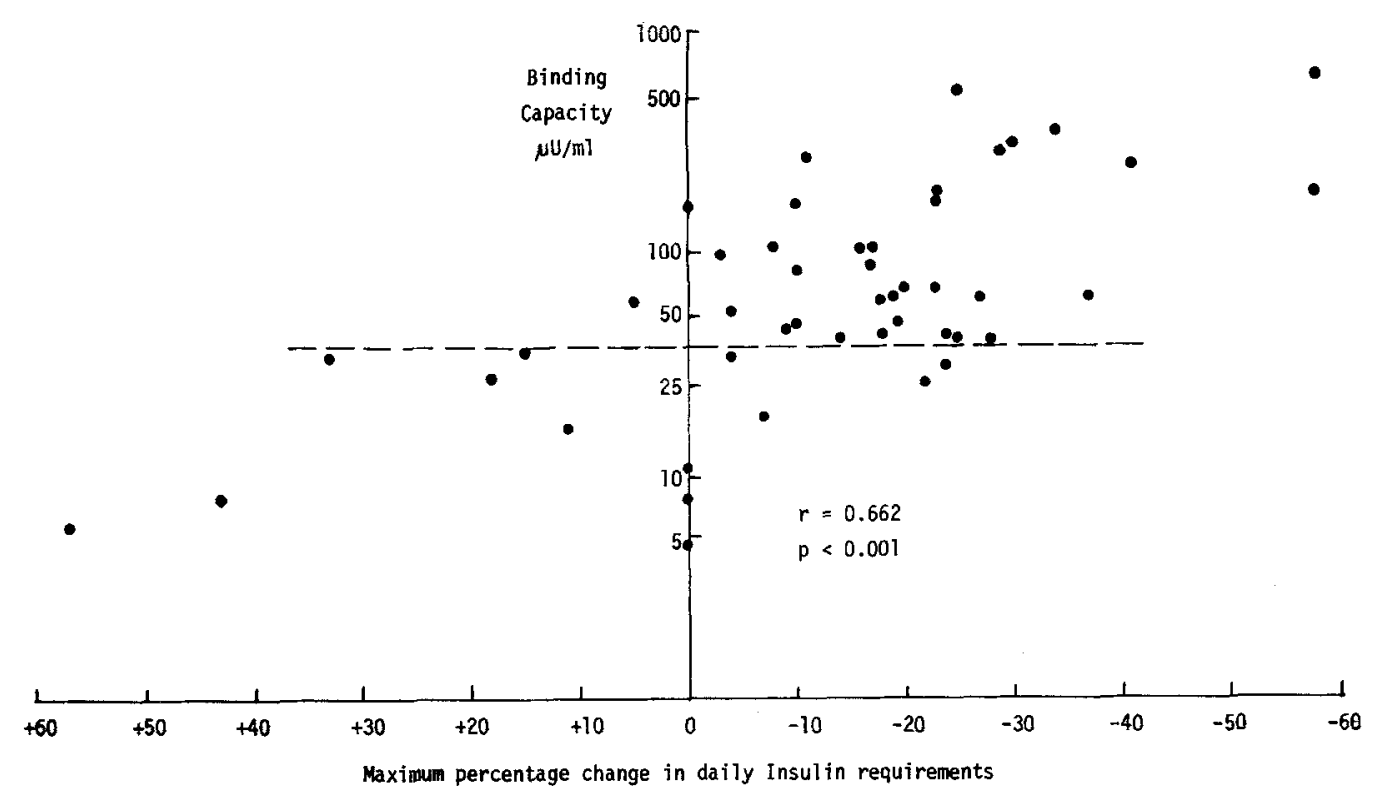

Fig. 1. Correlation between maximum percentage change in daily insulin requirement and initial insulin binding capacity (log scale) $(-)$ reduction, (+) increase in requirement. The broken line indicates an IBC of $40 \mu \mathrm{U} / \mathrm{ml}$

was not associated with deterioration of diabetic control. As indicated in the methods section assessment of diabetic control was based on a number of variables. Isolated blood sugar readings in the clinic at the time of the start of the highly purified insulins gave a mean of $13.1 \mathrm{mmol} / 1 \mathrm{SD} \pm 4.8$ and the average at 4,5 and 6 months was mean $12.3 \mathrm{mmol} / 1 \mathrm{SD}$ \pm 4.0. These figures are disappointingly high for well-motivated intelligent diabetics, but there is no evidence that control deteriorated. Figures for body weight have also been analysed. Mean body weight 1 year before the trial started was $64.68 \mathrm{~kg}$ (SD \pm 8.70 ), at the time of entry into the trial 64.19 (SD \pm 8.70 ) and after six months on the highly purified insulins 64.59 ( $\mathrm{SD} \pm 7.94)$. Neither of these changes is significant using the paired ' $t$ '-test. The patients' own assessment of their control and well-being cannot be quantitated, most of the patients were satisfied with the highly purified insulins, although six of them complained that hypoglycaemic attacks tended to occur rather earlier after an injection.

The change of insulin requirement during the six month period on the highly purified insulins varied from an increase of $12 \mathrm{U}$ to a reduction of $30 \mathrm{U} /$ day. Dose reduction was most likely when the IBC exceeded $40 \mu \mathrm{U} / \mathrm{ml}$. Of the 47 patients, 34 had an $\mathrm{IBC}>40 \mu \mathrm{U} / \mathrm{ml}$ and of these 32 showed a reduction of insulin dose. Of the 13 patients with an IBC of $<40 \mu \mathrm{U} / \mathrm{ml}$ only 4 showed a reduction of the dose. When the entire group is considered there is a significant correlation between the initial IBC and maximum change in daily insulin requirement $(r=$
$0.662, \mathrm{n}=47, \mathrm{P}<0.001$ ) (Fig. 1). The maximum reduction of insulin requirement was seen at 3-4 months, although in some patients it occurred in the first month and in three it was delayed until 6 months. In 3 patients the insulin requirement fell and then tended to increase; these were patients with an IBC $<40 \mu \mathrm{U} / \mathrm{ml}$. At 6 months the dose reduction and correlation with IBC were maintained $(\mathrm{r}=0.658, \mathrm{n}=47, \mathrm{p}<0.001)$.

Serial measurements of IBC were made on all patients. The IBC decreased in 29 patients and 28 of these had a reduction of insulin requirement. In 8 patients the IBC showed little change, but in 6 the insulin dose fell. In 10 patients IBC increased and 8 of these needed more insulin. Examples of the serial IBC levels are shown in Figures 2 and 3. To assess the relation between change of insulin requirement and serial IBC measurements, the patients were divided into two groups one showing a reduction of insulin dose and the other no change or an increase. In terms of change of IBC these two groups were found to be statistically distinct $(p<0.001$, Chisquare test with Yates' correction), suggesting that the antibody level is a factor in determining insulin requirement. This is supported by the correlation between initial insulin dose and IBC $(r=0.507, n$ $=47, \mathrm{p}<0.001$ ) shown in Figure 4.

\section{Discussion}

The development of highly purified insulins is a new stage in commercial insulin production. Bloom et 


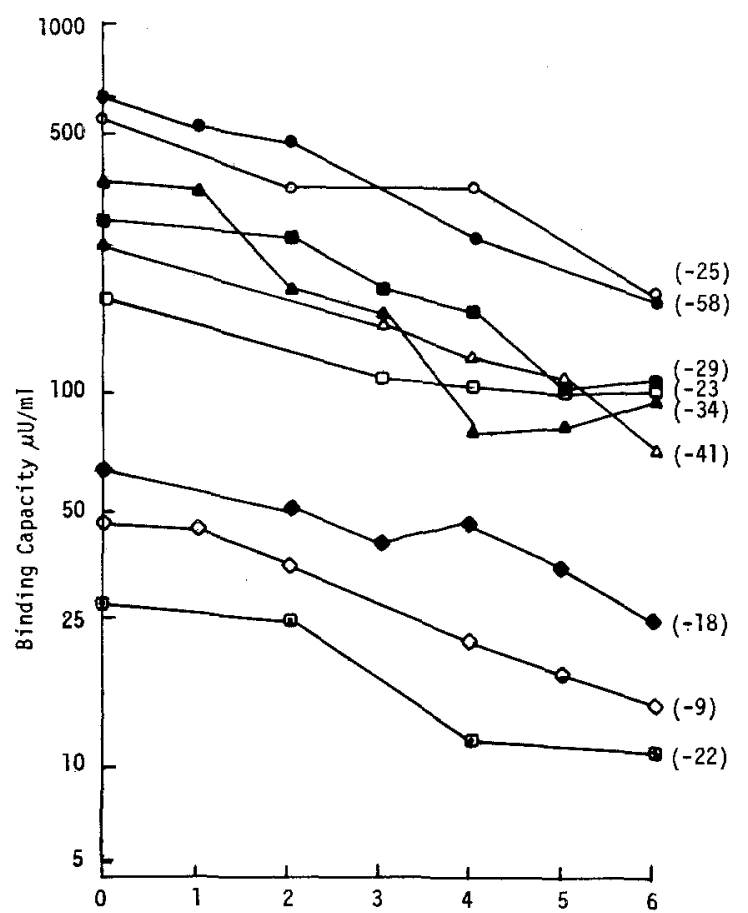

2 Duration on highly-purified Insulins (months)

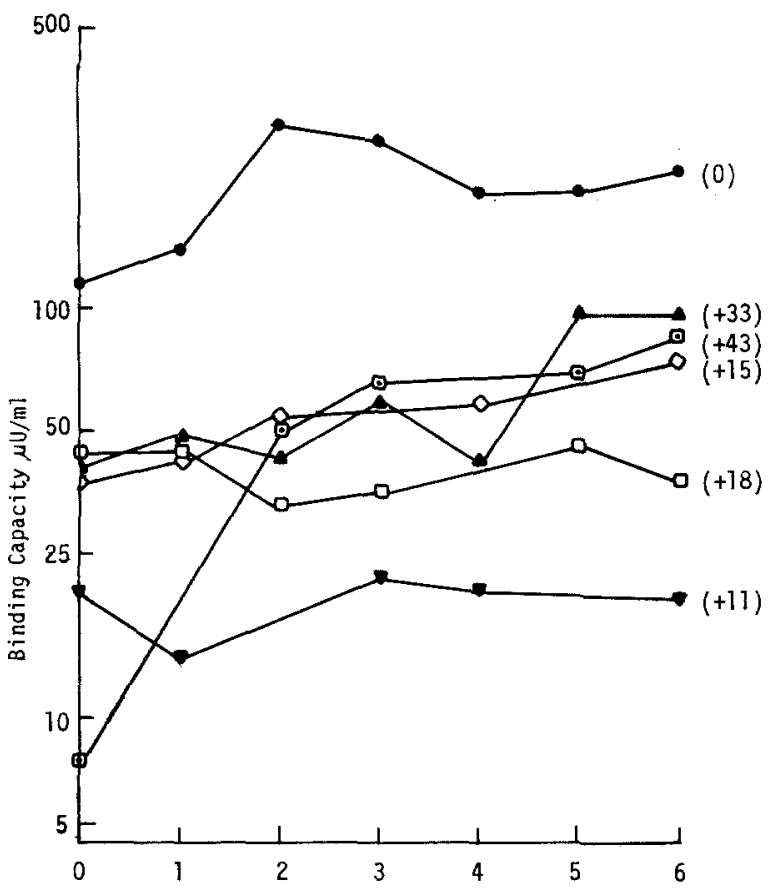

3 Duration on highly-purified Insulins (months)

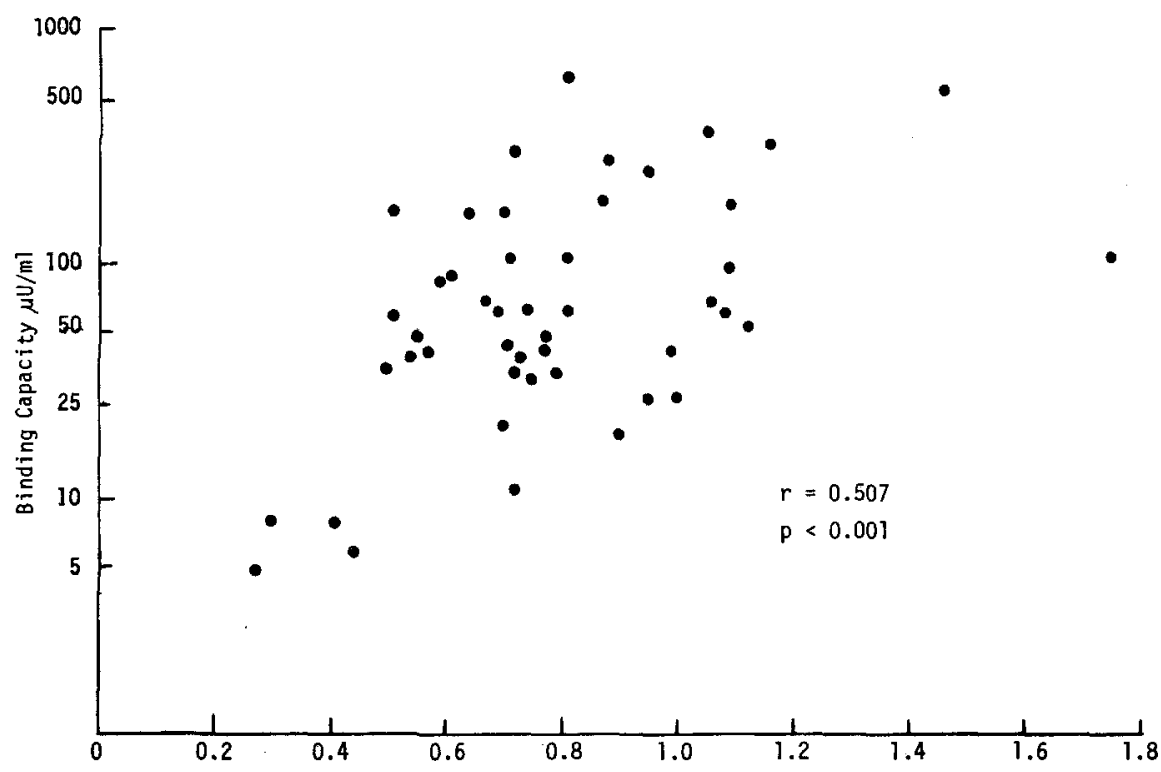

4

Daily Insulin requirements $(\mathrm{U} / \mathrm{kg} / \mathrm{d})$

Fig. 2. Changes in binding capacity (log scale) over 6 months in patients who responded with a reduction of insulin requirement. The maximum percentage change of the latter in each patient is shown in parentheses

Fig. 3. As Fig. 2 - patients who did not show a reduction of insulin requirement

Fig. 4. Initial daily insulin requirement as $U / \mathrm{kg}$ body weight in relation to initial insulin binding capacity $\mu \mathrm{U} / \mathrm{ml}$ (log scale)

al. [5] have demonstrated that many antigenic substances are present in currently available insulin preparations, and the consequent development of antibodies cannot be accepted with equanimity. It would seem reasonable to suggest that all diabetics receiving insulin for the first time should, whenever possible, be treated with a highly purified insulin, although it is clear that antibodies may still appear $[6,7,8]$. With patients already being treated with insulin the indications for changing to a highly purified preparation are less clear. If there is evidence of fat atrophy $[9,10]$, allergic reaction $[11$, 12] or insulin resistance a highly purified preparation should be tried. Other diabetics vary in their antibody response to insulin injections. Some have high levels and when these are changed to a highly purified preparation their insulin requirement usually drops $[1,2,3]$. Measurement of the IBC is a convenient method of ascertaining when there is likely to be a reduction of insulin requirement and will 
alert the physician of the need to guard against hypoglycaemic attacks $[13,14]$. With the Leo Neutral and Retard insulins the drop in requirement has been gradual and unexpected hypoglycaemia has not been a problem in our experience.

Our studies have confirmed that there is a correlation between insulin requirement and antibody level $[2,15,16,17]$. It appears that patients with a high level of antibodies 'waste' insulin. The mechanism of this is not clear. Though total immuno-reactive insulin has been shown to increase with antibody level [18], the major component of this is the bound form $[19,20]$ and is biologically inactive [21]. It is possible that much of this bound insulin is destroyed with the antibody by an immunological mechanism $[22,23]$ before it can dissociate and exert a physiological action. Although a high level of antibodies seems to be 'wasteful' of insulin, it has been suggested that the presence of antibodies may attenuate the rise of free insulin in the plasma shortly after an insulin injection and make for smoother control of the diabetes [24].

The modified IBC measurement described in this paper is a simple test for detecting patients with a high antibody level who are likely to be as well controlled on a smaller dose of a highly purified insulin.

Acknowledgements. We are very grateful to Mr. Colin Campbell of Nordisk Insulin Ltd., Langley, Berkshire, England for supplies of Leo Neutral and Leo Retard insulins, and to the Nordisk Foundation for financial support. We should also like to thank the Department of Medical Illustration of the Middlesex Hospital and Medical School for the figures. BEM is a British Council research fellow from the Universiti Kebangsaán, Kuala Lumpur, Malaysia.

\section{References}

1. Bruni, B., D'Alberto, M., Osenda, M., Ricci, C., Turco, G. L.: Clinical trial with monocomponent lente insulins. Diabetologia 9, 492-498 (1973)

2. Andreani, D., Iavicoli, M., Tamburrano, G., Menzinger, G.: Comparative trials with monocomponent (MC) and monospecies (MS) pork insulins in the treatment of diabetes mellitus. Influence on antibody levels, on insulin requirement and on some complications. Horm. Metab. Res. 6, 447-454 (1974)

3. Oakley, N. W.: Effect of "fractionated" insulins on total plasma insulin binding capacity and insulin requirement in severe diabetes. Lancet 1976 I, 994-996

4. Andersen, O.O., Brunfeldt, K., Abilgård, F.: A method for quantitative determination of insulin antibodies in human plasma. Acta Endocrinol. (Kbh.) 69, 195-208 (1972)

5. Bloom, S. R., Adrian, T.E., Mitchell, S.J., Barnes, A.J., Kohner, E. M.: Dirty insulin, a stimulant to autoimmunity? Diabetologia 12, 381 (1976)
6. Yue, D. K., Turtle, J. R.: Antigenicity of "monocomponent" pork insulin in diabetic subjects. Diabetes 24, 625-632 (1975)

7. Andersen, O.O.: The immunogenic properties of highlypurified insulin preparations. The clinical importance of insulin-binding antibodies. Acta Endocrinol. (Kbh.) 78, $723-735$ (1975)

8. Chance, R.E., Root, M.A., Galloway, J.A.: The immunogenicity of insulin preparations. Acta Endocrinol. (Kbh.) Suppl. 205, 185-196 (1976)

9. Teuscher, A.: Treatment of insulin lipoatrophy with monocomponent insulin. Diabetologia 10, 211-214 (1974)

10. Ferland, L., Ehrlich, R.M.: Single-peak insulin in the treatment of insulin-induced fat atrophy. J. Pediatr. 86, 741-743 (1975)

11. Davidson, J. A., Galloway, J. A., Petersen, B. H., Wentworth, S.M., Crabtree, R.E.: The use of purified insulins in insulin allergy. Diabetes 23, 352 (1974)

12. Vinik, A. I., Jackson, W.P. U.: Clinical aspects of "monocomponent" insulin in diabetes. Lancet $1975 \mathrm{II}, 548-550$

13. Logie, A. W., Stowers, J. M.: Hazards of monocomponent insulins. Br. Med. J 1976 I, 879-880

14. Asplin, C. M., Hartog, M.: Hazards of monocomponent insulins. Br. Med. J 1976 I, 1146

15. Yagi, Y., Maier, P., Pressman, D., Arbesman, C. E., Reisman, R.E., Lenzner, A.R.: Multiplicity of insulin binding antibodies in human sera. J. Immunol. 90, 760-769 (1963)

16. Kühnau, J., Meyer, H.W.: Circulating insulin neutralising insulin antibodies and their influence on the insulin treatment of diabetes mellitus. Excerpta Medica, Int. Congr. Ser, 140, 77 (1967)

17. Andersen, O.O.: Insulin antibody formation. The influence of age, sex, infections insulin dosage and regulation of diabetes. Acta Endocrinol. (Kbh.) 71, 126-140 (1972)

18. Schlichtkrull, J., Brange, J., Christiansen, A. H., Hallund, O., Heding, L.G., Jørgensen, K.H.: Clinical aspects of insulin antigenicity. Diabetes 21, 649-656 (1972)

19. Villalpando, S., Drash, A.: Total and free plasma insulin levels in children with long-standing diabetes mellitus. Diabetes 24, 447 (1975)

20. Gennaro, W. D., Van Norman, J. D.: Quantitation of free, total, and antibody-bound insulin in insulin-treated diabetics. Clin. Chem. 21, 873-879 (1975)

21. Antoniades, H.N., Simon, J.D.: Neutralisation of the biologic activity of human serum bound insulin by potent insulin antisera. Diabetes 21, 930-934 (1972)

22. Berson, S.A., Yalow, R.S.: Insulin antagonists, insulin antibodies and insulin resistance. Am. J. Med. 25, 155-159 (1958)

23. Frikke, M. J., Gingerich, R. L., Stranahan, P.D., Carter, G., Bauman, A.K., Greider, M.H., Wright, P.H., Lacy, P.E.: Distribution of injected insulin and insulin-antibody complexes in normal and insulin immunised animals. Diabetologia 10, 345-351 (1974)

24. Dixon, K., Exon, P.D., Malins, J.M.: Insulin antibodies and the control of diabetes, Q. J. Med. 44, 543-553 (1975)

Received: December 10,1976, and in revised form:

March 14, 1977

J.D.N. Nabarro

The Middlesex Hospital

London W1N 8AA

U. K. 